Article

\title{
Mesoporous polyoxometalate-based ionic hybrid as a highly effective heterogeneous catalyst for direct hydroxylation of benzene to phenol
}

\author{
Pingping Zhao *, Yunyun Zhang, Daokuan Li, Hongyou Cui \#, Lipeng Zhang \\ School of Chemical Engineering, Shandong University of Technology, Zibo 255049, Shandong, China
}

\section{A R T I C L E I N F O}

\section{Article history:}

Received 15 October 2017

Accepted 28 November 2017

Published 5 February 2018

\section{Keywords:}

Polyoxometalate

Mesoporous

Benzene hydroxylation

Heterogeneous catalyst

Phenol

\begin{abstract}
A B S T R A C T
Self-assembled mesoporous polyoxometalate-based ionic hybrid catalyst, [PxyDim $]_{2.5} \mathrm{PMoV}_{2}$, was prepared by combining $p$-xylene-tethered diimidazole ionic liquid [ $\mathrm{PxyDim}^{\mathrm{C} \mathrm{Cl}_{2}}$ with Keggin-structured $\mathrm{V}$-substituted polyoxometalate $\mathrm{H}_{5} \mathrm{PMo}_{10} \mathrm{~V}_{2} \mathrm{O}_{40}$. The obtained hybrid was shown to be a mesostructured and hydrophobic material with good thermal stability. In the $\mathrm{H}_{2} \mathrm{O}_{2}$-based hydroxylation of benzene to phenol, the hybrid showed extraordinary catalytic activity and rate, and quite stable reusability. The unique hydrophobic properties and mesoporous structure of the hybrid were responsible for its excellent catalytic performance.
\end{abstract}

(C) 2018, Dalian Institute of Chemical Physics, Chinese Academy of Sciences. Published by Elsevier B.V. All rights reserved.

\section{Introduction}

Phenol is among the main raw materials used in the chemical industry, including in the synthesis of resins, fungicides, preservatives, and pharmaceuticals. Industrially, phenol is produced by the three-step cumene process, which has high energy consumption and produces much environmental pollution [1]. Therefore, many attempts have been made to develop a one-step hydroxylation of benzene to phenol using different oxidants, such as $\mathrm{O}_{2}$ [2], $\mathrm{H}_{2} \mathrm{O}_{2}$ [3], and $\mathrm{N}_{2} \mathrm{O}$ [4], as well as $\mathrm{H}_{2}-\mathrm{O}_{2}$ systems with $\mathrm{Pd}$-based composite membrane reactors [5]. Schiff bases [6], vanadium-containing mesoporous carbon [7-11], TS-1 molecular sieves [12], Fe-based metal-organic frameworks (MOFs) [13], and polyoxometalates (POMs) [14-16] have been applied as catalysts in the environmentally friendly $\mathrm{H}_{2} \mathrm{O}_{2}$-based hydroxylation of benzene. Among them, V-containing POM catalysts have proven to be effective catalysts because of the relatively mild reaction conditions required for direct hydroxylation of benzene to phenol $[17,18]$. Unfortunately, isolating and recycling these catalysts is difficult because POMs readily dissolve in the polar reaction system. Therefore, the preparation of heterogeneous POMs for the direct hydroxylation of benzene has become an interesting and challenging task.

The immobilization of POMs onto porous supports is a commonly used strategy to heterogenize POMs catalyst [19]. However, this approach inevitably suffers from slow reaction rates and/or leaching of active sites. Recently, the modification of POMs with organic units, such as ionic liquids (ILs), organometallic complexes, organic polymers, and silica matrices, has

\footnotetext{
* Corresponding author. Fax: +86-533-2781213; E-mail: zhaopingping@sdut.edu.cn

\# Corresponding author. Fax: +86-533-2781213; E-mail: cuihy@sdut.edu.cn

This work was supported by the National Natural Science Foundation of China $(21506118,21476132,51574160)$ and Shandong Province Foundation for Outstanding Young Scientist (BS2014CL030).

DOI: 10.1016/S1872-2067(17)62991-7 | http://www.sciencedirect.com/science/journal/18722067 | Chin. J. Catal., Vol. 39, No. 2, February 2018
} 
been developed to prepare POM-based organic-inorganic hybrid heterogeneous catalysts [20-24]. In this context, the assembly of POMs with task-specific ionic liquid cations is a successful example that is beneficial for adjusting the solubility, redox properties, and surface microenvironment of POMs. Previously, we have reported a series of POM-based ionic hybrid catalysts prepared by combining ionic liquid cations with heteropolyanions, with the resulting ionic solids shown to be effective catalysts for the oxidation of sulfides and benzene [25-27]. Nevertheless, self-assembled ionic hybrids are nonporous and have low specific surface areas, which limit the heterogeneous catalytic activity in mass-transfer-controlled systems [28]. The direct hydroxylation of benzene using POM-based polymeric ionic hybrid heterogeneous catalysts has also been studied [29]. Despite the high specific surface areas and excellent performance obtained, complex steps and large amounts of organic solvent are required for catalyst preparation. Therefore, a simple approach to prepare a highly efficient heterogeneous POM-based catalyst with mesoporous structure and high specific surface area is required.

In contrast, it should be noted that highly hydrophobic organic frameworks in hybrid catalysts act as dynamic traps that can adsorb relatively nonpolar substrate molecules and easily desorb relatively polar product molecules [30,31]. Therefore, hydrophobic organic segments in hybrid catalysts can enhance the probability of interactions between the substrate and catalytic center, which would improve the catalytic activity and selectivity.

Accordingly, we herein report a highly hydrophobic mesoporous POM-based hybrid catalyst prepared by pairing V-containing POM anions with $p$-xylene-tethered diimidazole ionic liquid cations (Fig. 1). The catalysts not only exhibit enhanced catalytic activities for the direct hydroxylation of benzene with $\mathrm{H}_{2} \mathrm{O}_{2}$, but also facilitate catalyst recovery from the reaction system. The excellent catalytic performances of these catalysts are mostly attributed to the contributions of their porous structures and hydrophobic microenvironments.

\section{Experimental}

\subsection{Materials and analytic methods}

All chemicals, including benzene (99.5\%), acetonitrile (99.9\%), acetic acid (99.8\%), and dichloromethane (99.9\%), were purchased from Sinopharm Chemical Reagent Co., Ltd. and used without further purification.

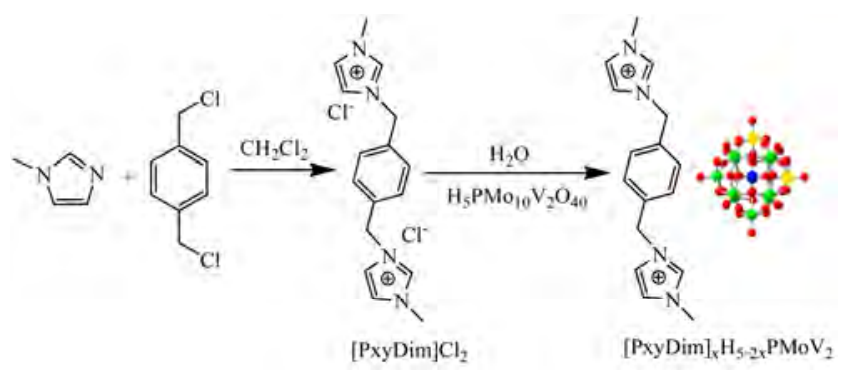

Fig. 1. Schematic preparation of ionic hybrid catalysts.
Fourier transform infrared (FT-IR) spectra were recorded on a Nicolet 360 FT-IR instrument (using $\mathrm{KBr}$ discs) in the wavenumber region 4000-400 $\mathrm{cm}^{-1}$. Elemental analysis was performed using a CHN elemental analyzer (Vario EL cube) and inductively coupling plasma spectrometer (ICP, Jarrell-Ash 1100). X-ray diffraction (XRD) patterns were recorded on a Bruker D8 Advance powder diffractometer using a Ni-filtered $\mathrm{Cu} K_{\alpha}$ radiation source at $40 \mathrm{kV}$ and $200 \mathrm{~mA}$, in the 2 range of $5^{\circ}-50^{\circ}$ at a scan rate of $2^{\circ} / \mathrm{min}$. Brunauer-Emmett-Teller (BET) surface areas were measured at the temperature of liquid nitrogen using a Micromeritics ASAP2010 analyzer. Samples were degassed at $150{ }^{\circ} \mathrm{C}$ to a pressure of $10^{-3}$ Torr before analysis. Scanning electron microscopy (SEM) images were recorded using a Hitachi S-4800 field-emission scanning electron microscope. Thermogravimetric (TG) analysis was conducted using a STA409 instrument in dry air at a heating rate of 10 ${ }^{\circ} \mathrm{C} / \mathrm{min}$.

\subsection{Catalyst preparation}

\subsubsection{Preparation of $\mathrm{H}_{5} \mathrm{PMo}_{10} \mathrm{~V}_{2} \mathrm{O}_{40}$}

$\mathrm{H}_{5} \mathrm{PMo}_{10} \mathrm{~V}_{2} \mathrm{O}_{40}$, herein abbreviated as $\mathrm{PMoV}_{2}$, was prepared according to our previous work [29]. In detail, $\mathrm{MoO}_{3}$ (16.59 g, $0.115 \mathrm{~mol}$ ) and $\mathrm{V}_{2} \mathrm{O}_{5}(2.1 \mathrm{~g}, 0.0115 \mathrm{~mol})$ were added to deionized water $(250 \mathrm{~mL})$, and heated to reflux under vigorous stirring, using a water-cooled condenser. An aqueous solution of $\mathrm{H}_{3} \mathrm{PO}_{4}$ (1.33 g, $0.0115 \mathrm{~mol}, 85 \mathrm{wt} \%$ ) was then added dropwise to the mixture. When the mixture became a clear orange-red solution, it was cooled to room temperature. $\mathrm{H}_{5} \mathrm{PMo}_{10} \mathrm{~V}_{2} \mathrm{O}_{40}$ was obtained as an orange-red powder after evaporating the solution to dryness and purification by recrystallization.

\subsubsection{Preparation of ionic liquid precursors}

Dicationic ionic liquid precursor $\left[\mathrm{PxyDim}^{\mathrm{C}} \mathrm{Cl}_{2}\right.$ was prepared as follows. Methylimidazole $(0.21 \mathrm{~mol})$ and $\alpha, \alpha$-dichloro- $p$-xylene $(0.10 \mathrm{~mol})$ were dissolved in dichloromethane $(50 \mathrm{~mL})$ at $35{ }^{\circ} \mathrm{C}$ under a nitrogen atmosphere and stirred for $48 \mathrm{~h}$. The solvent was then removed by distillation and the residue was washed with THF $(3 \times 30 \mathrm{~mL})$. After drying under a high vacuum, [PxyDim] $\mathrm{Cl}_{2}$ was obtained as a white solid in $95 \%$ yield.

Analogous ionic liquid [EthDim] $\mathrm{Cl}_{2}$ was prepared according to a literature procedure [20]. Methylimidazole $(0.21 \mathrm{~mol})$ and 1,2-dichloroethane $(0.10 \mathrm{~mol})$ were dissolved in isopropanol $\left(50 \mathrm{~mL}\right.$ ) at $80{ }^{\circ} \mathrm{C}$ under a nitrogen atmosphere and stirred for $48 \mathrm{~h}$. On reaction completion, the solvent was removed by distillation, and the product was dried under high vacuum to afford [EthDim] $\mathrm{Cl}_{2}$ as a colorless liquid in $83 \%$ yield. Ionic liquid [ButDim] $\mathrm{Cl}_{2}$ was synthesized using the same method. [BMim $] \mathrm{Cl}_{2}$ was synthesized according to a literature procedure [29].

\subsubsection{Preparation of polyoxometalate-based ionic hybrids}

Polyoxometalate (POM)-based ionic hybrids were prepared by reacting the ionic liquid precursors with $\mathrm{PMoV}_{2}$. In a typical procedure, [PxyDim]Cl 2 (5.0 mmol) and $\mathrm{PMoV}_{2}(2.0 \mathrm{mmol})$ were separately dissolved in deionized water $(2.0 \mathrm{mmol})$. The 
aqueous $\mathrm{PMoV}_{2}$ solution was added to the [PxyDim $] \mathrm{Cl}_{2}$ solution, followed by stirring at room temperature for $6 \mathrm{~h}$. The formed yellow precipitate was then filtered, washed with water $(3 \times 10 \mathrm{~mL})$ and ethanol $(3 \times 10 \mathrm{~mL})$, and dried under vacuum, affording [PxyDim $]_{2.5} \mathrm{PMoV}_{2}$. Using the above procedure, $[\text { PxyDim }]_{2} \mathrm{HPMoV}_{2}$ and $[\mathrm{PxyDim}] \mathrm{H}_{3} \mathrm{PMoV}_{2}$ were also prepared using the corresponding molar ratios of the respective reactants. Analogous hybrids [EthDim $]_{2.5} \mathrm{PMoV}_{2}$ and [ButDim] $2.5 \mathrm{PMoV}_{2}$ were also prepared accordingly.

\subsection{Catalyst evaluation}

Benzene (0.78 g, $10 \mathrm{mmol})$, a mixture of acetonitrile and acetic acid (volume ratio 1:1, $8 \mathrm{~mL}$ ), and catalyst $(0.1 \mathrm{~g})$ were added to a 25-mL flask reactor. Aqueous $\mathrm{H}_{2} \mathrm{O}_{2}$ (30 wt\%, 30 mmol) was then added dropwise to the stirred mixture in the reactor within $20 \mathrm{~min}$. The reaction time was recorded from when $\mathrm{H}_{2} \mathrm{O}_{2}$ addition was complete. The typical reaction temperature and time were $70{ }^{\circ} \mathrm{C}$ and $1 \mathrm{~h}$, respectively. After the reaction, the mixture was centrifuged to remove the solid catalyst, and the supernatant was analyzed by gas chromatography (GC) using an Agilent 7890B chromatograph equipped with a FID detector and capillary column (SE-54 $30 \mathrm{~m} \times 0.32 \mathrm{~mm} \times 0.3$ $\mu \mathrm{m})$. The GC oven temperature was held at $80{ }^{\circ} \mathrm{C}$ and then increased at $10{ }^{\circ} \mathrm{C} / \mathrm{min}$, holding at $100{ }^{\circ} \mathrm{C}$ for $2 \mathrm{~min}$ and $220{ }^{\circ} \mathrm{C}$ for $4 \mathrm{~min}$. Under the conditions employed, only phenol was detected as a product, with no GC signals for catechol, hydroquinone, or benzoquinone were observed. However, the reaction mixture changed to a dark color, probably due to the formation of heavy compounds (coke) that cannot be detected by GC. 1,4-Dioxane was used as an internal standard to calculate benzene conversion (benzene conversion = (initial benzene (mmol) - unconverted benzene (mmol)) / initial benzene $(\mathrm{mmol})$ ), phenol yield (phenol yield (based on benzene) $=$ phenol $(\mathrm{mmol}) /$ initial benzene $(\mathrm{mmol}))$, and the turnover number $\left(\mathrm{TON}=\right.$ phenol $(\mathrm{mmol}) / \mathrm{V}_{2}$ in catalyst $\left.(\mathrm{mmol})\right)$. To test catalytic recycling of $[\mathrm{PxyDim}]_{2.5} \mathrm{PMoV}_{2}$, the catalyst was separated by filtration after reaction, washed with acetonitrile $(3 \times$ $20 \mathrm{~mL}$ ), and dried under vacuum at $80{ }^{\circ} \mathrm{C}$ for $6 \mathrm{~h}$. The recovered catalyst was reused in the next run.

\section{Results and discussion}

\subsection{Catalyst characterization}

Elemental analysis results for $[\mathrm{PxyDim}]_{x} \mathrm{H}_{5-2 x} \mathrm{PMoV}_{2}$ are shown in Table 1 . The $\mathrm{C}, \mathrm{H}$, and $\mathrm{N}$ contents corresponded well

Table 1

Elemental analysis of [PxyDim $]_{x} \mathrm{H}_{5-2 x} \mathrm{PMoV}_{2}$.

\begin{tabular}{lccc}
\hline \multirow{2}{*}{ Catalyst } & \multicolumn{3}{c}{ Experimental results (calculated values)/wt $\%$} \\
\cline { 2 - 4 } & $\mathrm{C}$ & $\mathrm{N}$ & $\mathrm{H}$ \\
\hline$[\text { PxyDim }]_{2.5} \mathrm{PMoV}_{2}$ & $19.1(19.9)$ & $5.4(5.8)$ & $2.0(2.3)$ \\
{$[\text { PxyDim }]_{2} \mathrm{HPMoV}_{2}$} & $16.7(16.9)$ & $4.2(4.9)$ & $1.9(1.9)$ \\
{$\left[\right.$ PxyDim $\mathrm{H}_{3} \mathrm{PMoV}_{2}$} & $10.3(9.6)$ & $2.7(2.8)$ & $1.3(1.1)$ \\
Recycled & 19.0 & 5.6 & 1.9 \\
\hline
\end{tabular}

with the calculated results. TG analysis (Fig. 2) showed that the starting decomposition temperature of [DiPxyim $]_{2.5} \mathrm{PMoV}_{2}$ was about $270{ }^{\circ} \mathrm{C}$ (curve (1)), which was markedly higher than 200 ${ }^{\circ} \mathrm{C}$ for the ionic liquid (curve (2)). The drastic mass loss of nearly $25 \%$ in the temperature range $270-530{ }^{\circ} \mathrm{C}$ corresponded to thermal decomposition of organic cation [PxyDim] $]^{2+}$ in the hybrid. This phenomenon demonstrated the high thermal stability of [PxyDim $]_{2.5} \mathrm{PMoV}_{2}$ due to formation of the ionic hybrid $[25,26]$.

Fig. 3 shows the FT-IR spectra of IL [PxyDim] $\mathrm{Cl}_{2}$ and hybrid [PxyDim] $2.5 \mathrm{PMoV}_{2}$. The FT-IR spectrum of [PxyDim] $\mathrm{Cl}_{2}$ clearly shows characteristic bands at $1170-1630 \mathrm{~cm}^{-1}$ and $3010-3140$ $\mathrm{cm}^{-1}$ assigned to organic groups, indicating the coexistence of

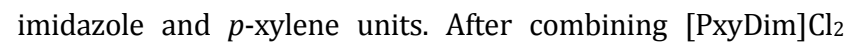
with $\mathrm{H}_{5} \mathrm{PMo}_{10} \mathrm{~V}_{2} \mathrm{O}_{40}$, the characteristic vibration bands for the $\left[\mathrm{PMo}_{10} \mathrm{~V}_{2} \mathrm{O}_{40}\right]^{5-}$ species were observed at $1054,947,868$, and $796 \mathrm{~cm}^{-1}$, attributed to $\mathrm{P}-\mathrm{O}_{\mathrm{a}}, \mathrm{Mo}=\mathrm{O}_{\mathrm{d}}, \mathrm{Mo}-\mathrm{O}_{\mathrm{b}}-\mathrm{Mo}$, and Mo- $\mathrm{O}_{c}-$ Mo vibrations, respectively. Moreover, the peaks assigned to the organic moiety in $[\mathrm{PxyDim}]_{2.5} \mathrm{PMoV}_{2}$ were only slightly shifted, indicating formation of hybrid [PxyDim] 2.5 $\mathrm{PMoV}_{2}$ via strong ionic bond interactions and hydrogen-bonding networks [32].

SEM images of [PxyDim] ${ }_{2.5} \mathrm{PMoV}_{2}$ (Fig. 4(a) and (b)) showed irregular honeycomb-shaped morphologies caused by the ac-

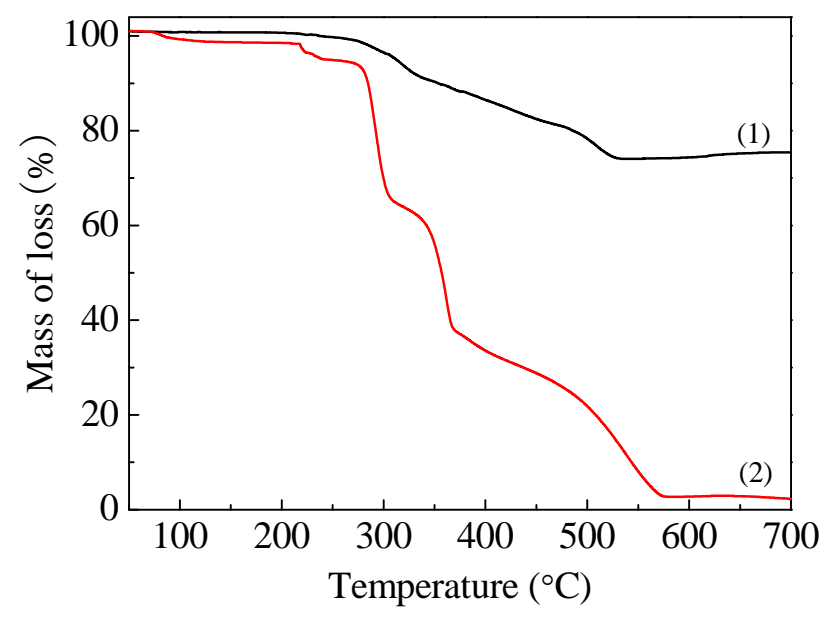

Fig. 2. TG curves of (1) [PxyDim $]_{2.5} \mathrm{PMoV}_{2}$ and (2) [PxyDim] $\mathrm{Cl}_{2}$.

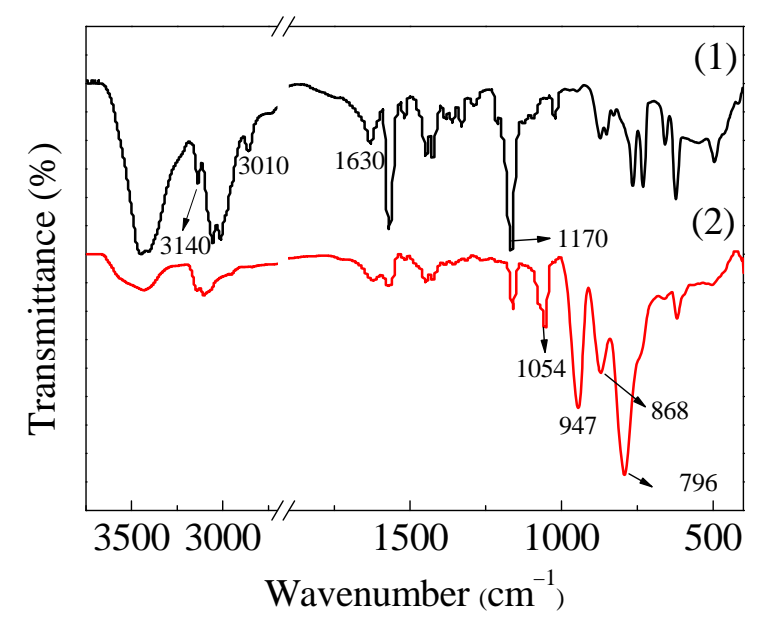

Fig. 3. FT-IR spectra of (1) [PxyDim]Cl $\mathrm{Cl}_{2}$ and (2) [PxyDim $]_{2.5} \mathrm{PMoV}_{2}$. 

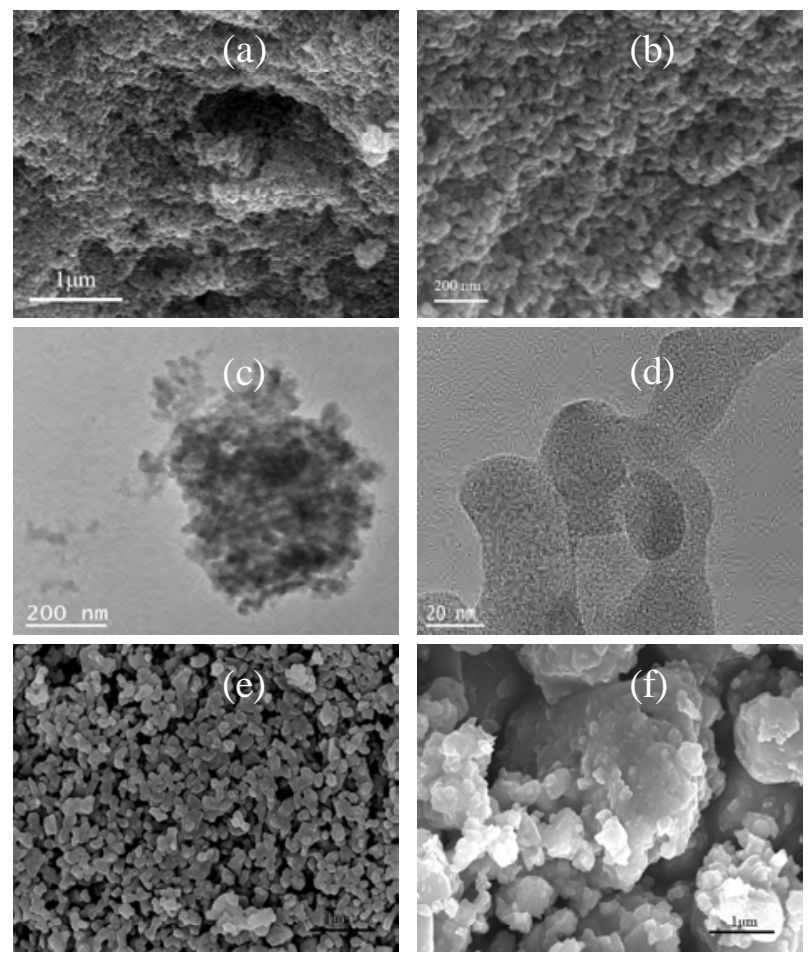

Fig. 4. $(\mathrm{a}, \mathrm{b}) \mathrm{SEM}$ images and (c, d) TEM images of $[\mathrm{PxyDim}]_{2.5} \mathrm{PMoV}_{2}$; SEM images of (e) [PxyDim] $\mathrm{H}_{3} \mathrm{PMoV}_{2}$ and (f) [EthDim] ${ }_{2.5} \mathrm{PMoV}_{2}$.

cumulation of the nanometer ball and nanoscale hollow structures, which might reflect the interconnected IL-POM secondary structure. TEM images of [PxyDim] $2.5 \mathrm{PMoV}_{2}$ (Fig. 4(c) and (d)) showed the existence of random mesopores among the intertwined particles and micropores of IL-cations and POM-anions. In the case of analogous hybrids [PxyDim] $\mathrm{H}_{3} \mathrm{PMoV}_{2}$ and [EthDim] $]_{2.5} \mathrm{PMoV}_{2}$ (Fig. 4(e) and (f)), the morphologies changed to an irregular micrometer-sized honeycomb-shaped morphology and angular blocks with a rough surface, respectively, due to packing of the nanoscale primary particles.

XRD patterns of pure $\mathrm{H}_{5} \mathrm{PMo}_{10} \mathrm{~V}_{2} \mathrm{O}_{40}$ and hybrid [PxyDim $]_{2.5} \mathrm{PMoV}_{2}$ are shown in Fig. 5. Characteristic sharp Bragg peaks observed for Keggin-type $\mathrm{H}_{5} \mathrm{PMo}_{10} \mathrm{~V}_{2} \mathrm{O}_{40}$ disap-

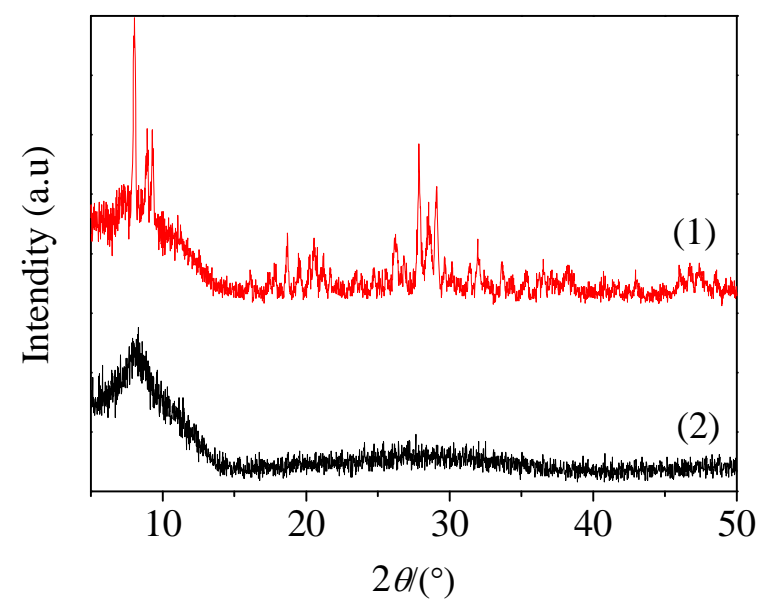

Fig. 5. XRD patterns of (1) $\mathrm{H}_{5} \mathrm{PMo}_{10} \mathrm{~V}_{2} \mathrm{O}_{40}$ and (2) $[\mathrm{PxyDim}]_{2.5} \mathrm{PMoV}_{2}$. peared for [PxyDim] $2.5 \mathrm{PMoV}_{2}$. For the latter, a new broad Bragg peak was detected at $2 \theta=8.1^{\circ}$, clearly showing that the hybrid had a noncrystal structure. This amorphous structure was in agreement with the SEM image (Fig. 4(b)). Therefore, it was concluded that hybrid [PxyDim] ${ }_{2.5} \mathrm{PMoV}_{2}$ possessed a noncrystal structure containing a certain regular ion-pair array.

The BET surface areas of [PxyDim $]_{2.5} \mathrm{PMoV}_{2}$ and the IL-POM analogues were characterized using nitrogen sorption experiments. As shown in Fig. 6, the isotherms of [PxyDim] $2.5 \mathrm{PMoV}_{2}$ were type IV with a clear H1-type hysteresis loop in the relative pressure $\mathrm{p} / \mathrm{p}_{\mathrm{o}}$ range of 0.8 to 1.0 , indicating the formation of mesoporous materials. The BET surface area and total pore volume were $58.5 \mathrm{~m}^{2} / \mathrm{g}$ and $0.44 \mathrm{~cm}^{3} / \mathrm{g}$, respectively (Table 2 , Entry 1). The most probable distribution of mesopores appeared at $29.9 \mathrm{~nm}$. However, control catalyst [EthDim $]_{2.5} \mathrm{PMoV}_{2}$, containing an alkyl group instead of $p$-xylene, was a nonporous material with a surface area of only $2.3 \mathrm{~m}^{2} / \mathrm{g}$ (Table 2, Entry 4). These results demonstrated that the $p$-xylene groups played important roles in the formation of mesoporous structures and encouraged us to prepare and test a series of catalysts [PxyDim] ${ }_{x} \mathrm{H}_{5-2 x} \mathrm{PMoV}_{2}$ with different molar ratios of [PxyDim] $]^{2+}$ to POM. The nitrogen sorption isotherms of the resultant samples are shown in Fig. 6. [PxyDim $]_{2} \mathrm{HPMoV}_{2}$ showed a typical type-IV isotherm in a pressure range of $0.8<$ $p / p_{0}<0.1$, a lower BET surface area $\left(49.3 \mathrm{~m}^{2} / \mathrm{g}\right)$ with a larger average mesopore size of $35.6 \mathrm{~nm}$, and a total pore volume of $0.44 \mathrm{~cm}^{3} / \mathrm{g}$ (Table 2, Entry 2). However, the lower $p$-xylene content gave nonporous hybrid material [PxyDim] $\mathrm{H}_{3} \mathrm{PMoV}_{2}$, which was consistent with the low surface area $\left(<10 \mathrm{~m}^{2} / \mathrm{g}\right)$ for common organic POM salts. In conclusion, two mesoporous IL-POM hybrid catalysts with moderate BET surface areas were

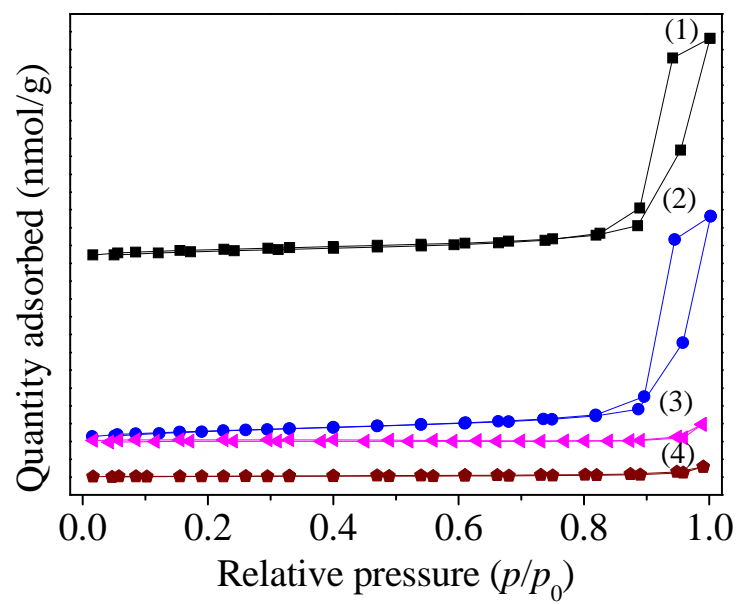

Fig. 6. $\mathrm{N}_{2}$ adsorption-desorption isotherms of (1) [PxyDim $]_{2.5} \mathrm{PMoV}_{2}$, (2) [PxyDim $]_{2} \mathrm{HPMoV}_{2}$, (3) [PxyDim] $\mathrm{H}_{3} \mathrm{PMoV}_{2}$, and (4) [EthDim $]_{2.5} \mathrm{PMoV}_{2}$.

\section{Table 2}

Textural parameters of various samples.

\begin{tabular}{lcccc}
\hline Entry & Sample & $S_{\text {BET }} /\left(\mathrm{m}^{2} / \mathrm{g}\right)$ & $V_{\mathrm{p}} \mathrm{b} /\left(\mathrm{m}^{3} / \mathrm{g}\right)$ & $D_{\mathrm{av}} \mathrm{c} / \mathrm{nm}$ \\
\hline 1 & {$[\text { PxyDim }]_{2.5} \mathrm{PMoV}_{2}$} & 58.5 & 0.44 & 29.9 \\
2 & {$\left[\right.$ PxyDim ${ }_{2} \mathrm{HPMoV}_{2}$} & 49.3 & 0.44 & 35.6 \\
3 & {$\left[\right.$ PxyDim] $\mathrm{H}_{3} \mathrm{PMoV}_{2}$} & 6.2 & 0.03 & 21.7 \\
4 & {$[\text { EthDim }]_{2.5} \mathrm{PMoV}_{2}$} & 2.3 & 0.02 & 27.7 \\
\hline
\end{tabular}

${ }^{a}$ BET surface area. ${ }^{b}$ Total pore volume. ${ }^{c}$ Average pore size. 
obtained by adjusting the $p$-xylene content.

\subsection{Catalytic activity}

Table 3 compares the performances of various catalysts in the hydroxylation of benzene with $\mathrm{H}_{2} \mathrm{O}_{2}$. No phenol was detected without catalyst or in the presence IL precursor [PxyDim] $\mathrm{Cl}_{2}$ or V-free $\mathrm{H}_{3} \mathrm{PMo}_{12} \mathrm{O}_{40}$ (Entries 1-3). When $\mathrm{H}_{5} \mathrm{PMo}_{10} \mathrm{~V}_{2} \mathrm{O}_{40}$ was used as the catalyst, a high phenol yield of $29.7 \%$ was achieved, with $30.2 \%$ conversion and a TON of 51.7 (Entry 4), consistent with the proposal that $\mathrm{V}$ ions in POM-anions are catalytically active centers for the hydroxylation of benzene to phenol [19,20,23]. However, pure $\mathrm{H}_{5} \mathrm{PMo}_{10} \mathrm{~V}_{2} \mathrm{O}_{40}$ is a homogeneous catalyst that is difficult to isolate and reuse. A phenol yield of $27.4 \%$ and TON of 57.1 were obtained using the known single cation ionic hybrid [BMim] $]_{2.5} \mathrm{PMoV}_{2}$ (Entry 5). Noticeably, [BMim] ${ }_{2.5} \mathrm{PMoV}_{2}$ was insoluble during the early reaction stage, but gradually dissolved with $\mathrm{H}_{2} \mathrm{O}_{2}$ addition, resulting in a homogeneous reaction. The results indicated that achieving an insoluble and highly active POM catalyst for heterogeneous hydroxylation of benzene with $\mathrm{H}_{2} \mathrm{O}_{2}$ was difficult because Keggin-structured HPA catalysts are labile, degradable, and soluble in the presence of $\mathrm{H}_{2} \mathrm{O}_{2}$ [33].

Interestingly, newly synthesized mesoporous catalyst [PxyDim $]_{2.5} \mathrm{PMoV}_{2}$ was not only insoluble in the reaction me-
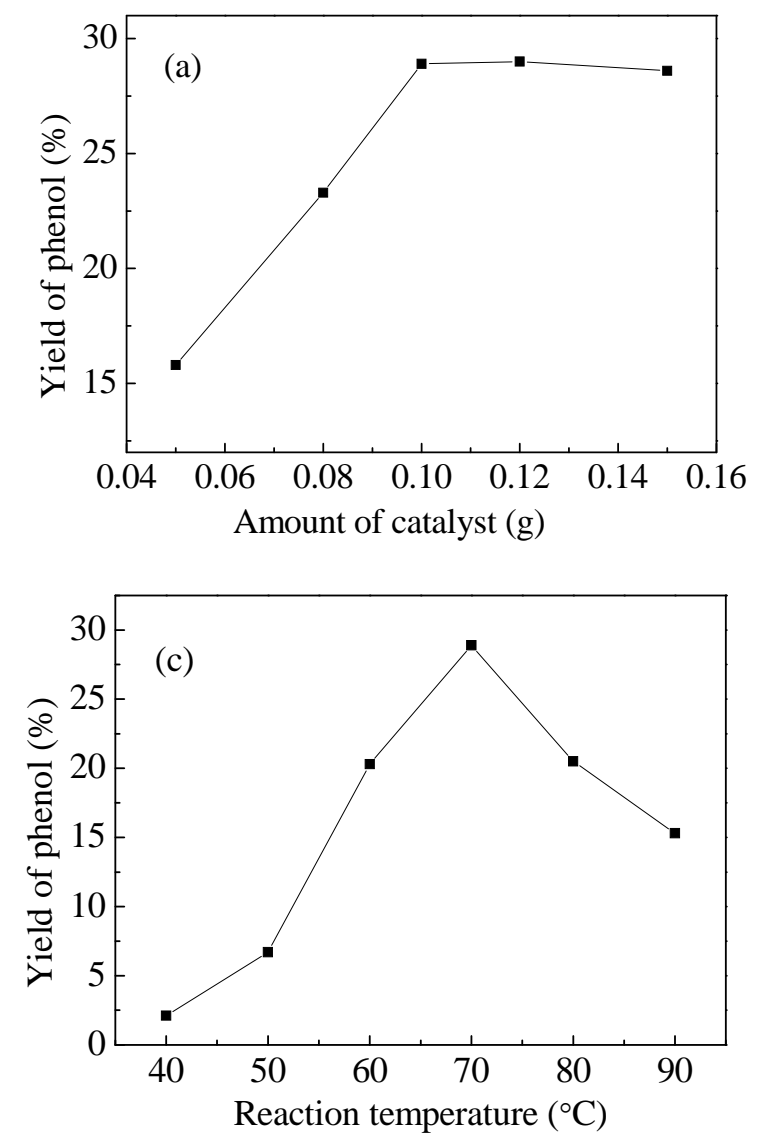

Table 3

Catalytic performances of various catalysts for the hydroxylation of benzene with $\mathrm{H}_{2} \mathrm{O}_{2}$ a.

\begin{tabular}{|c|c|c|c|c|c|}
\hline Entry & Catalyst & Solubility in reaction & $C^{\mathrm{b} / \%}$ & $Y^{\mathrm{c}} / \%$ & $\mathrm{TON}^{\mathrm{d}}$ \\
\hline 1 & none & - & 0 & 0 & 0 \\
\hline 2 & {$[\mathrm{PxyDim}] \mathrm{Cl}_{2}$} & soluble & 0 & 0 & 0 \\
\hline 3 & $\mathrm{H}_{3} \mathrm{PMo}_{12} \mathrm{O}_{40}$ & soluble & 0 & 0 & 0 \\
\hline 4 & $\mathrm{H}_{5} \mathrm{PMo}_{10} \mathrm{~V}_{2} \mathrm{O}_{40}$ & soluble & 30.2 & 29.7 & 51.7 \\
\hline 5 & {$[\mathrm{BMim}]_{2.5} \mathrm{PMoV}_{2}$} & soluble & 28.0 & 27.4 & 57.1 \\
\hline 6 & {$[\text { PxyDim }]_{2.5} \mathrm{PMoV}_{2}$} & insoluble & 29.4 & 28.9 & 69.5 \\
\hline 7 & {$[\text { PxyDim }]_{2} \mathrm{HPMoV}_{2}$} & insoluble & 24.6 & 24.5 & 55.7 \\
\hline 8 & {$[$ PxyDim $] \mathrm{H}_{3} \mathrm{PMoV}_{2}$} & insoluble & 19.5 & 18.9 & 37.8 \\
\hline 9 & {$[\text { EthDim }]_{2.5} \mathrm{PMoV}_{2}$} & insoluble & 15.5 & 14.6 & 32.4 \\
\hline 10 & {$\left[\right.$ ButDim] ${ }_{2.5} \mathrm{PMoV}_{2}$} & insoluble & 20.7 & 20.7 & 47.0 \\
\hline
\end{tabular}

a Reaction conditions: catalyst $0.1 \mathrm{~g}$, benzene $10 \mathrm{mmol}$, mixed solvent (acetonitrile/acetic acid) $8 \mathrm{~mL}, 1: 1(\mathrm{v} / \mathrm{v}) ; 30 \mathrm{wt} \% \mathrm{H}_{2} \mathrm{O}_{2}, 30 \mathrm{mmol}, 70{ }^{\circ} \mathrm{C}$; $1 \mathrm{~h} .^{\mathrm{b}}$ Benzene conversion. ${ }^{\mathrm{c}}$ Phenol yield. ${ }^{\mathrm{d}}$ Turnover number.

dium, but also afforded a rather high conversion (29.4\%) and phenol yield (28.9\%), with the highest TON of 69.5 (Entry 6). This result was obtained under optimized conditions after systematic investigation of various reaction parameters, including amount of catalyst, reaction time, reaction temperature, and molar ratio of $\mathrm{H}_{2} \mathrm{O}_{2}$ to benzene, as shown in Fig. 7. This catalytic
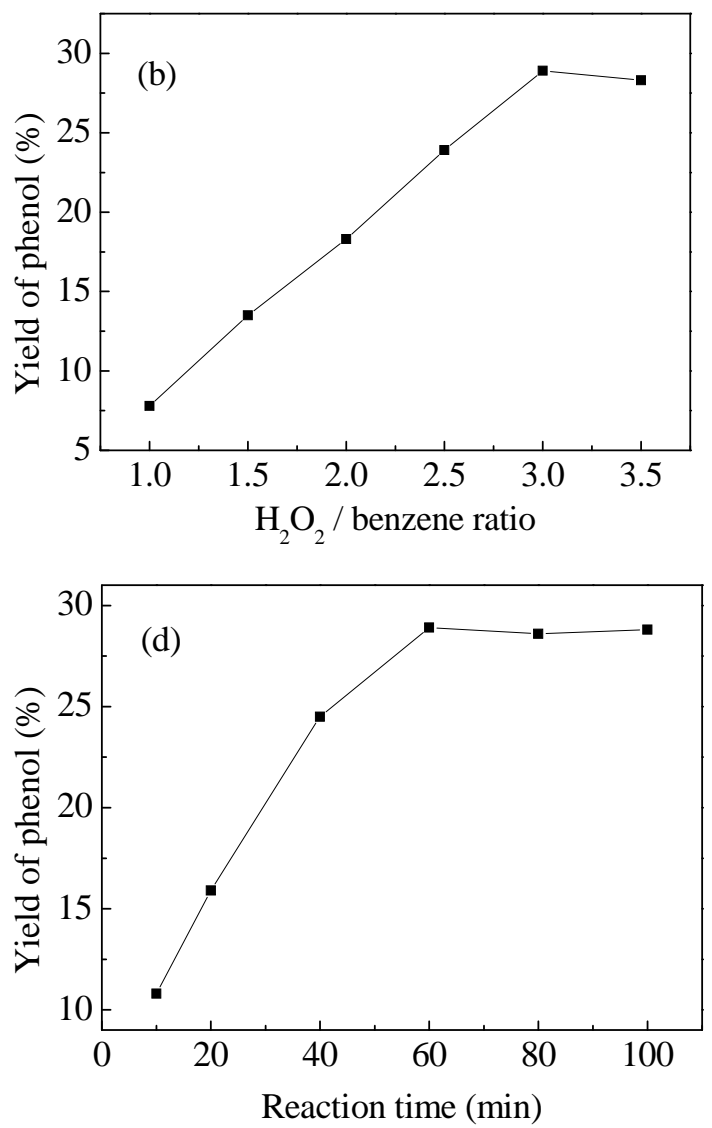

Fig. 7. Influence of reaction conditions on the hydroxylation of benzene with $\mathrm{H}_{2} \mathrm{O}_{2}$ over [PxyDim] ${ }_{2.5} \mathrm{PMoV}_{2}$ : (a) Catalyst amount; (b) Molar ratio of $\mathrm{H}_{2} \mathrm{O}_{2}$ to benzene; (c) Reaction temperature; (d) Reaction time. General reaction conditions: catalyst 0.1 g, benzene $10 \mathrm{mmol}, 30 \mathrm{wt} \% \mathrm{H}_{2} \mathrm{O}_{2} 30 \mathrm{mmol}$, acetonitrile/acetic acid $8 \mathrm{~mL}, 1: 1(\mathrm{v} / \mathrm{v}) ; 70{ }^{\circ} \mathrm{C}, 1 \mathrm{~h}$. 
performance was comparable to that of homogeneous $\mathrm{H}_{5} \mathrm{PMo}_{10} \mathrm{~V}_{2} \mathrm{O}_{40}$, suggesting no significant decline in the activity of the $\mathrm{V}$ species after heterogenization.

Mesoporous sample [PxyDim] ${ }_{2} \mathrm{HPMoV}_{2}$, containing a 2:1 molar ratio of [PxyDim] $]^{2+}$ to POM, was also a heterogeneous catalyst and gave an excellent phenol yield (24.5\%) and TON of 55.7 (Entry 7). Nevertheless, [PxyDim] ${ }_{2.5} \mathrm{PMoV}_{2}$ showed higher BET surface area $\left(58.5 \mathrm{~m}^{2} / \mathrm{g}\right)$ with a smaller average mesopore size of $29.9 \mathrm{~nm}$ (Table 2, Entries 1,2). This catalyst was more conducive to the reaction because more active sited were exposed. Therefore, the phenol yield of [PxyDim $]_{2} \mathrm{HPMoV}_{2}$ was slightly lower than that of [PxyDim] $2.5 \mathrm{PMoV}_{2}$. In contrast, nonporous sample [PxyDim] $\mathrm{H}_{3} \mathrm{PMoV}_{2}$ with a $1: 1$ molar ratio of [PxyDim $]^{2+}$ to POM gave a phenol yield of only $18.9 \%$ and TON of 37.8 (Entry 8), which might due to the lower BET surface area $\left(6.2 \mathrm{~m}^{2} / \mathrm{g}\right)$ and smaller total pore volume of $0.03 \mathrm{~cm}^{3} / \mathrm{g}$ (Table 2, Entry 3). As a result, the mesoporous structure seemed to play a key role in the excellent performance of [PxyDim] $]_{2.5} \mathrm{PMoV}_{2}$.

To clearly determine the role of the organic cation, two control samples, [EthDim] 2.5 $\mathrm{PMoV}_{2}$ and [ButDim] $2.5 \mathrm{PMoV}_{2}$, were prepared using different alkyl groups in place of $p$-xylene in the cation. Catalyst [EthDim] ${ }_{2.5} \mathrm{PMoV}_{2}$ afforded a phenol yield of only $14.6 \%$ and TON of 32.4 (Entry 9), which were both much lower than those of [PxyDim] $\mathrm{H}_{3} \mathrm{PMoV}_{2}$. [ButDim] ${ }_{2.5} \mathrm{PMoV}_{2}$, with a longer alkyl group, afforded a slightly better phenol yield $(20.7 \%)$ and TON of 47 (Entry 10). Furthermore, it has been reported that hydrophobic organic segments in a hybrid catalyst are beneficial for the hydroxylation of benzene due to the enhanced encapsulability with nonpolar benzene and promoted release of slightly polar phenol [30,31]. In summary, the above comparisons further indicated that the hydrophobic $p$-xylene units were indispensable for obtaining high POM catalyst activities for the hydroxylation of benzene to phenol using $\mathrm{H}_{2} \mathrm{O}_{2}$. Furthermore, this group might also supply a different microenvironment within the internal holes of the catalyst for reactions and strongly affect the catalytic activity.

Furthermore, catalytic kinetics tests were performed for selected samples [PxyDim $]_{2.5} \mathrm{PMoV}_{2}, \quad[\mathrm{PxyDim}]_{2} \mathrm{HPMoV}_{2}$, $[\text { PxyDim }]_{3} \mathrm{PMoV}_{2}$, [EthDim $]_{2.5} \mathrm{PMoV}_{2}$, and [ButDim $]_{2.5} \mathrm{PMoV}_{2}$, which had significantly different morphologies and pore structures (Fig. 8). In addition to a phenol yield of nearly $25 \%$ after a reaction time of $40 \mathrm{~min}$, mesoporous [PxyDim] $]_{2.5} \mathrm{PMoV}_{2}$, with an irregular honeycomb-shaped morphology due to the accumulation of nanometer balls, exhibited the fastest reaction rate, which was much higher than that of mesoporous $[\text { PxyDim }]_{2} \mathrm{HPMoV}_{2}$ with a similar honeycomb-shaped morphology caused by the accumulation of larger particles. Nonporous [PxyDim] $\mathrm{H}_{3} \mathrm{PMoV}_{2}$ and [ButDim] ${ }_{2.5} \mathrm{PMoV}_{2}$ showed almost uniform reaction rates, which were higher than that of [EthDim] 2.5 $\mathrm{PMoV}_{2}$. Such differences in the reaction rates further demonstrated that the mesoporous structure and hydrophilic-hydrophobic properties of the organic cation in the catalyst were related to their catalytic activity in the heterogeneous hydroxylation of benzene to phenol using $\mathrm{H}_{2} \mathrm{O}_{2}$.

\subsection{Catalytic reusability}

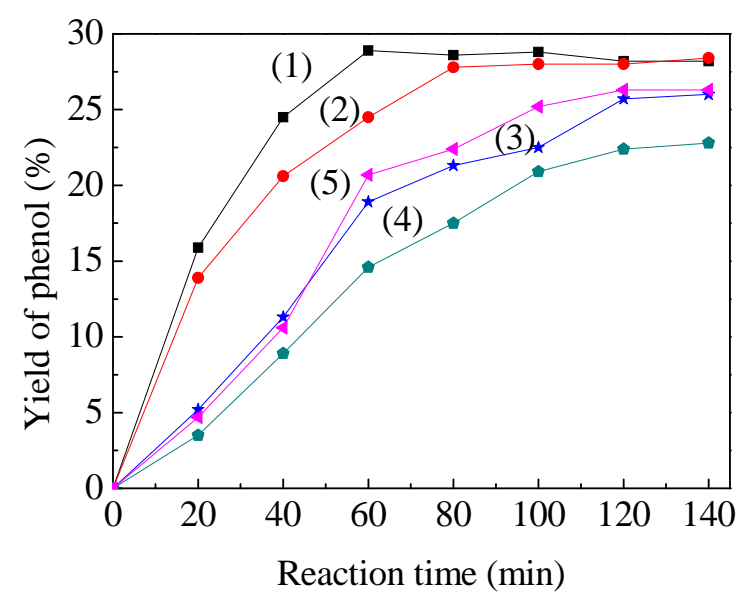

Fig. 8. Catalytic kinetics of (1) [PxyDim $]_{2.5} \mathrm{PMoV}_{2}$, (2) $[\mathrm{PxyDim}]_{2} \mathrm{HPMoV}_{2}$ (3) $[\mathrm{PxyDim}] \mathrm{H}_{3} \mathrm{PMoV}_{2}$, (4) $[\text { EthDim }]_{2.5} \mathrm{PMoV}_{2}$, and (5) $[\text { ButDim }]_{2.5} \mathrm{PMoV}_{2}$.

Catalyst reusability is especially important for practical applications. The catalytic recyclability of $[\mathrm{PxyDim}]_{2.5} \mathrm{PMoV}_{2}$ was measured using four-run successive experiments, as shown in Fig. 9(a). If no fresh catalyst was added to the recovered catalyst, the yield decreased slowly, affording 25.2\%, 23.7\%, and $23 \%$ yields on the second, third, and fourth runs, respectively. The IR spectrum of the recovered catalyst was almost identical to that of the fresh catalyst (Fig. 9(b)). Elemental analysis of the recovered catalyst showed $\mathrm{C}, \mathrm{H}$, and $\mathrm{N}$ contents of $19.0 \%, 1.9 \%$, and $5.6 \%$ (Table 1), which were very close to those of the fresh catalyst, with no significantly enhanced $\mathrm{C}$ content observed in the recycled catalyst. Furthermore, $\mathrm{V}$ was not observed in the heat recyclable filtrate by ICP-AES analysis. These results indicated that the slow decrease in yield was due to the slight physical loss of catalytic active sites during the reaction and recovery rather than coke formation on the catalyst surface or structural distortion.

When a small amount of fresh catalyst was added to the recovered catalyst to compensate for catalyst loss during recycling after each run, the decline in phenol yield was negligible. This phenomenon not only suggested that heterogeneous catalyst [PxyDim $]_{2.5} \mathrm{PMoV}_{2}$ was reusable after a simple filtration, but also that the decrease in activity of the recovered catalyst was due to physical leaching of catalytic active centers, in contrast to conventional supported catalysts, which are mostly deactivated due to coking [34].

\section{Conclusions}

A new mesoporous polyoxometalate-based ionic hybrid catalyst, [PxyDim $]_{2.5} \mathrm{PMoV}_{2}$, has been successfully synthesized for the heterogeneous hydroxylation of benzene using $\mathrm{H}_{2} \mathrm{O}_{2}$, showing an enhanced phenol yield and robust recyclability. This highly efficient catalytic performance was attributed to the hydrophobic microenvironment provided by the nonpolar organic moiety in the hybrid, and the mesoporous structure, which enhanced the diffusion of benzene into reactive $V_{2}$ centers and desorption of the phenol product. These promising 

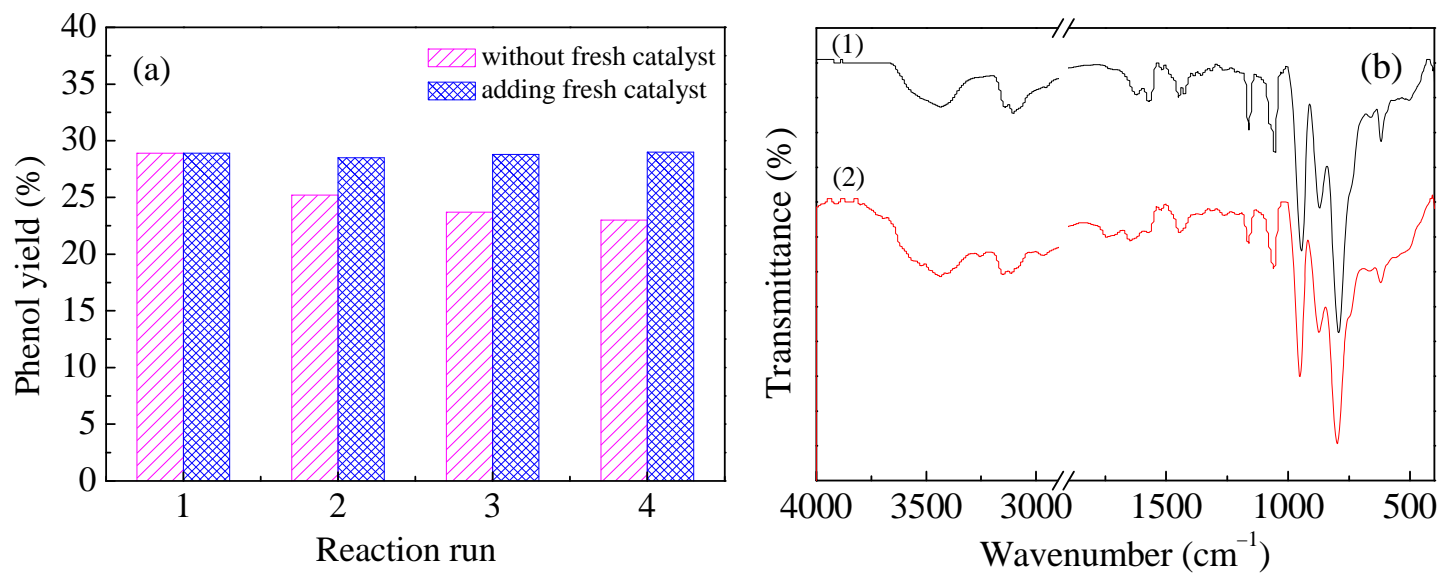

Fig. 9. (a) Catalytic reusability of $[\mathrm{PxyDim}]_{2.5} \mathrm{PMoV}_{2}$ in the hydroxylation of benzene using $\mathrm{H}_{2} \mathrm{O}_{2}$. Reaction conditions: $\mathrm{H}_{2} \mathrm{O}_{2} /$ benzene molar ratio $3: 1$; acetonitrile/acetic acid $8 \mathrm{~mL}, 1: 1(\mathrm{v} / \mathrm{v}) ; 70^{\circ} \mathrm{C} ; 1 \mathrm{~h}$. (b) FT-IR spectra of (1) [PxyDim] ${ }_{2.5} \mathrm{PMoV}_{2}$ and (2) recycled [PxyDim]2.5PMoV 2.

results have encouraged us to extend our research to develop mesoporous POM-based ionic hybrid catalysts for other heterogeneous $\mathrm{H}_{2} \mathrm{O}_{2}$-based organic oxidations.

\section{References}

[1] H. Hock, S. Lang, Ber. Dtsch. Chem. Ges. B, 1944, 77, 257-264.

[2] B. B. Sarma, R. Carmieli, A. Collauto, I. Efremenko, J. M. L. Martin, R. Neumann, ACS. Catal., 2016, 6, 6403-6407.

[3] Y. Morimoto, S. Bunno, N. Fujieda, H. Sugimoto, S. Itoh, J. Am. Chem. Soc., 2015, 137, 5867-5870.

[4] H. C. Xin, A. Koekkoek, Q. H. Yang, R. Van Santen, C. Li, E. J. M. Hensen, Chem. Commun., 2009, 7590-7592.

[5] S. I. Niwa, M. Eswaramoorthy, J. Nair, A. Raj, N. Itoh, H. Shoji, T. Namba, F. Mizukami, Science., 2002, 295, 105-107.
[6] P. K. Khatri, B. Singh, S. L. Jain, B. Sain, A. K. Sinha, Chem. Commun., 2011, 47, 1610-1612.

[7] L. Y. Hu, C. Wang, L. Ye, Y. N. Wu, B. Yue, X. Y. Chen, H. Y. He, Appl. Catal. A, 2015, 504, 440-447.

[8] J. Xu, Q. Jiang, T. Chen, F. Wu, Y. X. Li, Catal. Sci. Technol., 2015, 5, 1504-1513.

[9] J. Xu, Y. Chen, Y. Hong, H. Zheng, D. Ma, B. Xue, Y. X. Li, Appl. Catal. A, 2018, 549, 31-39.

[10] G. D. Wen, S. C. Wu, B. Li, C. L. Dai, D. S. Su, Angew. Chem. Int. Ed., 2015, 54, 4105-4109.

[11] H. F. Wang, M. Zhao, Q. Zhao, Y. F. Yang, C. Y Wang, Y. J. Wang, Ind. Eng. Chem. Res., 2017, 56, 2711-2721.

[12] L. Balducci, D. Bianchi, R. Bortolo, R. D’Aloisio, M. Ricci, R. Tassinari, R. Ungarelli, Angew. Chem. Int. Ed., 2003, 42, 4937-4940.

[13] D. K. Wang, M. T. Wang, Z. H. Li, ACS Catal., 2015, 5, 6852-6857.

\section{Graphical Abstract}

Chin. J. Catal., 2018, 39: 334-341 doi: 10.1016/S1872-2067(17)62991-7

Mesoporous polyoxometalate-based ionic hybrid as a highly effective heterogeneous catalyst for direct hydroxylation of benzene to phenol

Pingping Zhao*, Yunyun Zhang, Daokuan Li, Hongyou Cui *, Lipeng Zhang

Shandong University of Technology

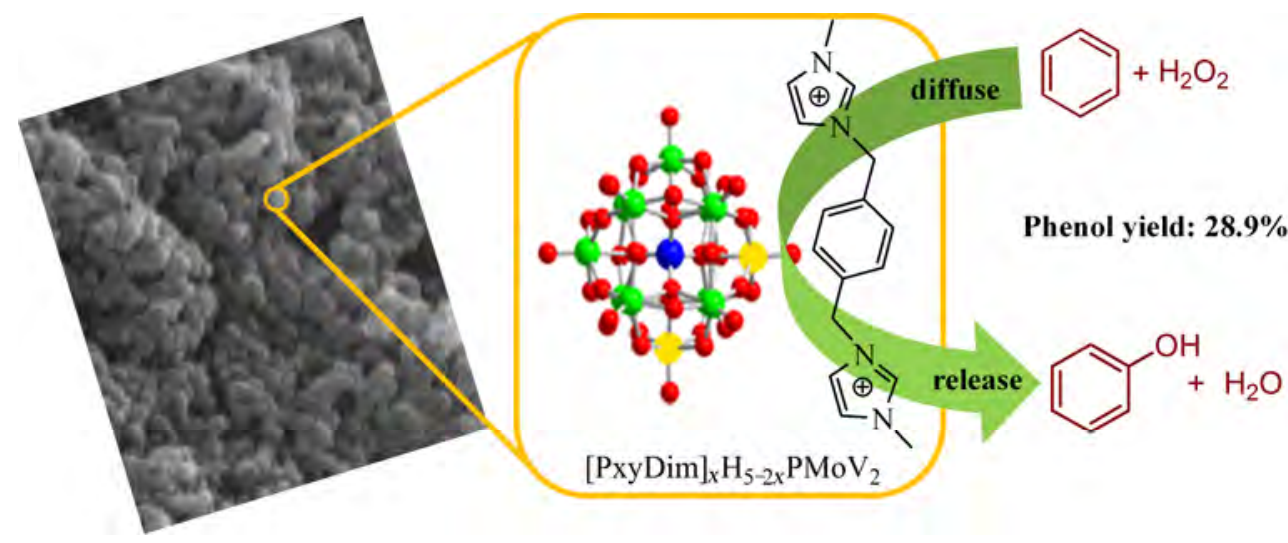

A mesoporous polyoxometalate-based ionic hybrid was developed as a heterogeneous catalyst for $\mathrm{H}_{2} \mathrm{O}_{2}$-based hydroxylation of benzene to phenol. The hydrophobic microenvironment and mesoporous structure were responsible for its efficient catalytic performance. 
[14] K. Nomiya, K. Yagishita, Y. Nemoto, T. A. Kamataki, J. Mol. Catal. A, 1997, 126, 43-53.

[15] Z. Y. Long, G. J. Chen, S. Liu, F. M. Huang, L. M. Sun, Z. L. Qin, Q. Wang, Y. Zhou, J. Wang, Chem. Eng. J., 2018, 334, 873-881.

[16] P. P. Zhao, Y. Zhou, Y. Q. Liu, J. Wang, Chin. J. Catal., 2013, 34, 2118-2124.

[17] K. Nomiya, S. Matsuoka T. Hasegawa, Y. Nemoto, J. Mol. Catal. A, 2000, 156, 143-152.

[18] J. Zhang, Y. Tang, G. Y. Li, C. W. Hu, Appl. Catal. A, 2005, 278, 251-261.

[19] A. N. Kharat, S. Moosavikia, B. T. Jahromi, A. Badiei, J. Mol. Catal. A, 2011, 348, 14-19.

[20] Y. Leng, J. Wang, D. R. Zhu, L. Shen, P. P. Zhao, M. J. Zhang, Chem. Eng. J., 2011, 173, 620-626.

[21] A. Proust, B. Matt, R. Villanneau, G. Guillemot, P. Gouzerh, G. Izzet, Chem. Soc. Rev., 2012, 41, 7605-7622.

[22] Y. Leng, J. Wang, D. R. Zhu, M. J. Zhang, P. P. Zhao, Z. Y. Long, J. Huang, Green Chem., 2011, 13, 1636-1639.

[23] C. Zou, Z. J. Zhang, X. Xu, Q. H. Gong, J. Li, C. D. Wu, J. Am. Chem. Soc., 2012, 134, 87-90.
[24] Y. Leng, J. Liu, P. P. Jiang, J. Wang, Chem. Eng. J., 2014, 239, 1-7.

[25] P. P. Zhao, M. J. Zhang, Y. J. Wu, J. Wang, Ind. Eng. Chem. Res., 2012, 51, 6641-6647.

[26] P. P. Zhao, Y. Leng, M. J. Zhang, J. Wang, Y. J. Wu, J. Huang, Chem. Commun., 2012, 48, 5721-5723.

[27] P. P. Zhao, J. Wang, G. J. Chen, Y. Zhou, J. Huang, Catal. Sci. Technol., 2013, 3, 1394-1404.

[28] S. Uchida, K. Kamata, Y. Ogasawara, M. Fujita, N. Mizuno, Dalton Trans., 2012, 41, 9979-9983.

[29] P. P. Zhao, Y. Leng, J. Wang, Chem. Eng. J., 2012, 204-206, 72-78.

[30] A. Nisar, Y. Lu, J. Zhuang, X. Wang, Angew. Chem. Int. Ed., 2011, 50, 3187-3192.

[31] C. Li, Z. X. Jiang, J. B. Gao, Y. X. Yang, S. J. Wang, F. P. Tian, F. X. Sun, X. P. Sun, P. L. Ying, C. R. Han, Chem. Eur. J., 2004, 10, 2277-2280.

[32] A. C. Templeton, W. P. Wuelfing, R. W. Murray, Acc. Chem. Res., 2000, 33, 27-36.

[33] A. Brückner, G. Scholz, D. Heidemann, M. Schneider, D. Herein, U. Bentrup, M. Kant, J. Catal., 2007, 245, 369-380.

[34] J. C. Yori, J. M. Grau, V. M. Benitez, J. Sepulveda, Appl. Catal. A, 2005, 286, 71-78.

\title{
基于多金属氧酸盐的介孔离子催化剂催化苯一步氧化制苯酚
}

\author{
赵萍萍*, 张云云, 李道宽, 崔洪友\#, 张丽鹏 \\ 山东理工大学化工学院, 山东淄博255049
}

摘要: 苯酚是一种重要的有机化工原料, 工业上主要采用合成路线长、原子利用率低、能耗高、环境污染严重的异丙苯法 生产. 当前, 随着绿色化学的普及, $\mathrm{H}_{2} \mathrm{O}_{2}$ 催化苯一步氧化制苯酚受到越来越多的关注. 在研究的众多催化剂中, 钒取代杂多 酸被认为是该反应最有效的催化剂之一. 然而, 纯杂多酸易溶于 $\mathrm{H}_{2} \mathrm{O}_{2}$ 催化的苯羟基化反应体系, 导致污染严重、后处理和 分离困难. 为了获得可回收的固体杂多酸催化剂, 通常将其负载于多孔载体上, 但这种方法常伴随着活性组分易溶脱, 反 应速率慢等缺点. 因此, 在 $\mathrm{H}_{2} \mathrm{O}_{2}$ 催化苯一步氧化制苯酚体系中获得高效、可重复使用的杂多酸基固体催化剂仍然是一个挑 战.

采用有机单元修饰杂多酸是制备杂多酸基固体催化剂的有效方法. 研究表明, 有机基团的引入可以有效调控杂多酸 的溶解性和氧化还原性. 另一方面, 催化剂中的疏水微环境也能有效促进非极性底物与催化活性中心的相互作用, 提高反 应速率, 改善催化活性. 因此, 我们通过离子交换法将对二甲苯型双核咪唑离子液体阳离子与含钒杂多阴离子结合, 研究 制备了一种具有疏水微环境的介孔杂多酸基离子固体催化剂. 采用傅里叶变换红外光谱、 $\mathrm{X}$ 射线衍射、扫描电镜、 $\mathrm{N}_{2}$ 吸附 -脱附和CHN元素分析等表征手段对催化剂进行全面分析. 结果表明, 该催化剂是一种具有较高比表面积的半无定形疏水 有机杂多酸盐. 在 $\mathrm{H}_{2} \mathrm{O}_{2}$ 催化的苯一步氧化制苯酚反应中引导了液-固两相催化体系, 在反应时间 $1 \mathrm{~h}$, 反应温度 $70{ }^{\circ} \mathrm{C}$, 苯酚产 率可达到 $28.9 \%$, 与均相纯杂多酸的催化活性基本相当, 且催化剂重复使用性能良好. 催化剂构效关系和反应动力学研究 表明, 高比表面积和疏水微环境的构建加快了苯与催化活性中心的相互作用, 提高了催化反应速率和产物选择性. 同时, 咪唑基离子液体阳离子通过分子内的电子相互作用改善了杂多阴离子的氧化还原能力, 也赋予固体催化剂更高的催化活 性. 该研究为 $\mathrm{H}_{2} \mathrm{O}_{2}$ 催化苯一步氧化制苯酚反应提供了一种制备简单, 经济高效, 可重复使用的杂多酸基固体催化剂. 关键词: 多金属氧酸盐; 介孔; 苯羟基化; 多相催化; 苯酚

收稿日期: 2017-10-15. 接受日期: 2017-11-28. 出版日期: 2018-02-05.

*通讯联系人. 传真: (0533)2781213; 电子信箱：zhaopingping@sdut.edu.cn

\#通讯联系人. 传真: (0533)2781213; 电子信箱: cuihy@sdut.edu.cn

基金来源: 国家自然科学基金(21506118, 21476132, 51574160); 山东省中青年科学家奖励基金(BS2014CL030).

本文的电子版全文由Elsevier出版社在ScienceDirect上出版(http://www.sciencedirect.com/science/journal/18722067). 